\title{
Práticas intersetoriais nas politicas públicas de promoção de saúde
}

\section{I ${ }^{1}$ Elaine de Azevedo, ${ }^{2}$ Maria Cecília Focesi Pelicioni, ${ }^{3}$ Marcia Faria Westphal I}

Resumo: Esta revisão analisa algumas políticas públicas estabelecidas entre 2006 e 2010 que dialogam com as diretrizes da Promoção da Saúde, de modo a investigar como a intersetorialidade perpassa suas ações. A intersetorialidade tem o potencial de revitalizar tais políticas, estimulando ações promotoras da saúde que contemplem os complexos condicionantes do processo saúde-doença. Entretanto, evidenciam-se alguns problemas para atingir esse desafio. Destacam-se o despreparo político e técnico de gestores e profissionais da saúde para assumir ações intersetoriais e questôes de ordem administrativa que dificultam a execução integrada de açôes. Tal despreparo leva, entre outros danos, à falta de reconhecimento de alguns dos temas das políticas como questões legítimas de Saúde Coletiva. Além disso, permanecem em muitas das agendas das políticas, decisões centralizadas que impedem a participação da comunidade e o surgimento de problemas ajustados às realidades locais, cujas soluções exigem intervenções intersetoriais e criativas. Assim, torna-se essencial fomentar um efetivo processo educativo interdisciplinar que forme profissionais da saúde com visão intersetorial em sintonia com as diretrizes das políticas públicas de promoção da saúde. Também é importante valorizar a dimensão territorial e as redes sociais, potencializando processos participativos que ampliem a perspectiva intersetorial dessas políticas, bem como estimular a ativação do sujeito nos processos decisórios.

> Palavras-chave: intersetorialidade; promoção da saúde; políticas públicas.

\author{
1 Pós-doutoranda da \\ Faculdade de Saúde Pública \\ da Universidade de São \\ Paulo (FSP/USP); doutora \\ e professora adjunta da \\ Faculdade de Ciências da Saúde \\ Universidade Federal da Grande \\ Dourados. Endereço eletrônico: \\ elainepeled@gmail.com \\ 2 Professora associada no \\ Departamento de Prática \\ de Saúde Pública (FSP/ \\ USP). Endereço eletrônico: \\ ceciliafocesipelicioni@yahoo. \\ com.br \\ ${ }^{3}$ Professora Titular no \\ Departamento de Prática \\ de Saúde Pública (FSPI \\ USP). Endereço eletrônico: \\ marciafw@usp.br
}


A intersetorialidade aparece recorrentemente nos estudos da Saúde Coletiva, com grande ênfase entre os pressupostos da promoção da saúde. Esta revisão não-sistemática objetiva conhecer como as práticas intersetoriais estão sendo incorporadas nas ações previstas em diferentes redes, políticas, programas e planos públicos, estabelecidos entre 2006 e 2010, que dialogam com as diretrizes da promoção da saúde. Naturalmente, uma das políticas centrais nesta análise será a Política Nacional de Promoção da Saúde, PNPS. Para compor a análise, também serão utilizadas as planilhas ainda não publicadas de uma avaliação interna realizada por técnicos da Secretaria de Vigilância da Saúde do Ministério da Saúde, de matriciamento dos avanços e desafios das prioridades da PNPS que analisam as ações propostas e realizadas em 2006 e 2009 (BRASIL, 2010e).

A perspectiva intersetorial tenta atender à questão de que os problemas reais cruzam os setores e têm atores que se beneficiam ou são prejudicados por eles (INOJOSA, 1998). Os problemas de saúde são parte dessa complexa questão, de causalidade múltipla, que afeta as populações, necessitando da articulação de saberes e experiências para seus enfrentamentos (JUNQUEIRA, 1998).

Propostas de ação intersetorial questionam a predominância do setor saúde para resolver problemas que circundam o binômio saúde-doença, considerando a impossibilidade desse único setor de lidar com questôes como as doenças e agravos não-transmissíveis e a mortalidade por causas externas. Assim, exigem-se novas estratégias para seu enfrentamento, ultrapassando atuações setoriais.

\section{Referencial teórico}

O conceito de intersetorialidade foi bem definido por Feuerwerker e Costa (2000, p. 94):

[...] a articulação entre sujeitos de setores sociais diversos e, portanto, de saberes, poderes e vontades diversos, para enfrentar problemas complexos. É uma nova forma de trabalhar, de governar e de construir políticas públicas que pretende possibilitar a superação da fragmentação dos conhecimentos e das estruturas sociais para produzir efeitos mais significativos na saúde da população.

Tal conceito reverbera no ideário de promoção da saúde, compreendido como um novo paradigma da Saúde Pública, um processo orientado por uma visão de saúde que considera as diversas causas do binômio saúde-doença, a partir de 
valores éticos de democratização, de estímulo à participação social e equidade e de promoção da sustentabilidade, a partir de açôes intersetoriais.

Dentro da PNPS, compreende-se a intersetorialidade

[...] como uma articulação das possibilidades dos distintos setores de pensar a questão complexa da saúde, de corresponsabilizar-se pela garantia da saúde como direito humano e de cidadania, e de mobilizar-se na formulação de intervenções que a propiciem (BRASIL, 2006a, p.13).

Trabalha-se em promoção da saúde com a ideia de "responsabilização múltipla”, de Buss (2000, p. 164), propondo-se a articulação de saberes técnicos e populares, além da mobilização de recursos institucionais e comunitários, públicos e privados para o enfrentamento e resolução dos problemas (PELICIONI, 2005; WESTPHAL, 2006).

Campos e colaboradores (2005) destacam outros aspectos que dialogam com a temática da intersetorialidade na promoção da saúde, inserindo novos atores na discussão. Tal ideário delineia-se como uma política que deve transitar em todos os níveis de complexidade da gestão e da atenção do sistema de saúde, e para isso precisa mobilizar usuários e profissionais da saúde como “protagonistas na organização do processo produtivo em saúde" envolvidos em um "processo de construção compartilhada", a partir de atitudes dialógicas, flexíveis e generosas (p. 747).

Dentro dessa perspectiva, esses autores questionam a construção de ações intersetoriais que sejam apenas a soma de diferentes olhares interdisciplinares sobre um mesmo objeto, sem a participação dos atores envolvidos na problemática em questão. Questionam também estratégias singulares aplicadas sobre os diferentes territórios e populaçōes. Para eles, a prática da intersetorialidade deve responder às necessidades de saúde das diferentes coletividades, mobilizando os setores necessários para isso e envolvendo a população em todas as etapas de implantação das ações. Amplia-se, assim, a discussão sobre a autonomia, sem desqualificar a centralidade do papel do Estado na melhoria das condições de vida e na formulação de políticas públicas.

Dentro das estratégias de fomento à intersetorialidade, busca-se a formação de redes descentralizadas, complexas e heterogêneas, para estabelecer o "sentido da unidade na diversidade”, como sugere Luck, citado por Mendes e Akerman (2007, p. 90). Além da afinidade com o conceito de rede, a intersetorialidade dialoga com a ideia de rizoma, um sistema aberto, acentrado, não-hierárquico, de ligações 
intercambiáveis que se opõe a sistemas centrados, de comunicação hierárquica e ligaçooes pré-estabelecidas que não se rompem (DELEUZE; GUATTARI, 1995). Para Mendes (1996), a intersetorialidade, uma prática a ser estabelecida em territórios específicos, apresenta no campo do fazer os mesmos desafios relacionados à construção coletiva que a interdisciplinariedade tem no campo do saber.

Do ponto de vista das autoras deste artigo, a intersetorialidade - e a perspectiva de integralidade nela implícita - busca o estabelecimento de parcerias entre diferentes instituições no sentido de trabalharem juntos para o alcance de objetivos e metas comuns. Consiste na obtenção de certa unidade, apesar das diferentes áreas de atuação dos setores envolvidos, tentando estabelecer vínculos intencionais que superem a fragmentação e a especialização.

Assume-se portanto, neste estudo, que a prática da intersetorialidade na saúde propõe um diálogo e ações complementares entre setores diversos, sem desconsiderar a necessidade de integrar ações dentro de cada setor. Ou seja, podese dizer que ao buscar a intersetorialidade, espera-se encontrar ações conjuntas que perseguem o mesmo objetivo entre setores diferentes; entre o público e o privado e entre a sociedade civil e o Estado em instâncias nas quais essas dicotomias ainda persistem. Já o termo intrassetorialidade tem a mesma proposta de integração, mas refere-se, neste artigo, a açōes dentro de um mesmo setor - no caso, o setor saúde. A intrassetorialidade se mescla ao conceito de integralidade que, para a PNPS significa, além da articulação e sintonia entre as estratégias de produção da saúde dentro do setor saúde, também a ampliação da escuta dos trabalhadores e serviços de saúde na relação com os usuários, considerando suas necessidades e condições de vida (BRASIL, 2006a).

Ressalta-se que, apesar de destacar essas diferenças entre os termos intersetorialidade, integralidade e intrassetorialidade, ao longo do artigo, tais práticas integrativas podem se mesclar sob o conceito único de intersetorialidade.

\section{A Política Nacional de Promoção da Saúde (PNPS)}

A coordenação da PNPS no SUS e sua articulação com os demais setores governamentais e não-governamentais são atribuídas a um comitê gestor que reúne todas as secretarias do Ministério da Saúde, suas fundações, agências, Conselho Nacional de Secretários Municipais de Saúde e Conselho Nacional de Secretários Estaduais de Saúde, incentivando a elaboração, por parte dos estados, 
Distrito Federal e municípios, de políticas de promoção da saúde locais que considerem as diretrizes da PNPS (BRASIL, 2008a).

Essa política, homologada em 2006, apresenta diferentes esferas de ações que indicam sua intenção de atuar de forma intersetorial. Apresenta como diretrizes: o reconhecimento da busca da equidade; o estímulo às ações intersetoriais; o fortalecimento da participação social; a promoção das mudanças na cultura organizacional; o incentivo à pesquisa e a divulgação das iniciativas voltadas para a promoção da saúde, considerando metodologias participativas e o saber popular (BRASIL, 2006a).

Tais diretrizes devem ser relevadas como tentativas de atingir os desafiantes objetivos da promoção da saúde, sem que se ignorem as críticas às ações efetivamente adotadas por essa política. Para Verdi e Caponi (2005), tais críticas são importantes em um momento em que ainda se formula conceitualmente a promoção da saúde, no qual se corre o risco de construir políticas reducionistas que transformam problemas complexos "em desvios de conduta individuais, deslocando tanto o cerne da questão do corpo social para o corpo biológico ou físico, quanto à responsabilidade da produção de respostas efetivas do nível do Estado para o próprio indivíduo" (p. 85). Segundo essas autoras, é o reducionismo que explica a adoção de estratégias de informação e incentivo às mudanças de estilos de vida individuais, o que significa manter o enfoque preventivista.

Após a implantação da PNPS, o Ministério da Saúde (MS) impulsionou a formação e qualificação da Rede Nacional de Promoção da Saúde através de um seminário realizado em 2006. Atualmente, fazem parte dessa rede $26,3 \%$ dos municípios no país, além de 27 estados com projetos de promoção da saúde em desenvolvimento (GOSCH, 2007).

Considerando a necessidade de integração e continuidade das ações de promoção da saúde, o MS estabeleceu o mecanismo de repasse financeiro do Fundo Nacional de Saúde aos Fundos de Saúde Estaduais, Municipais e do Distrito Federal para a realização de ações específicas da PNPS. O ministério criou uma portaria e enfatizou a integração das ações da Estratégia de Saúde da Família com as de Vigilância em Saúde, Promoção da Saúde e Prevenção de Doenças e Agravos não-Transmissíveis (BRASIL, 2010a; BRASIL, s/d).

Os recursos citados por esta portaria destinaram-se a promover a continuidade de propostas de ações apresentadas pelos entes que compóem a rede nacional 
financiada através de editais de forma a ampliar a Rede Nacional de Núcleos de Prevenção de Violências e Promoção da Saúde, relativos às ações específicas da PNPS: promoção da atividade física e de alimentação saudável; redução da morbidade por acidentes de trânsito; prevenção da violência e estímulo à cultura da paz; redução da morbidade em decorrência do uso abusivo de álcool e outras drogas; prevenção e controle do tabagismo e promoção do desenvolvimento sustentável (BRASIL, 2010a).

Destacam-se, entre outras, as ações da rede voltadas para a produção de conhecimentos e capacitação através de cursos. Nesse sentido, foram proporcionadas diferentes opçōes, como o Curso Internacional de Avaliação de Projetos de Promoção da Saúde (2009); e o curso de extensão para Gestores do SUS em Promoção da Saúde (2010), com tecnologia à distância, que formou 540 gestores e/ou coordenadores dos projetos financiados pelo MS. Outro curso à distância, "Impactos da Violência na Saúde" (2007), para gestores municipais e estaduais de todo o país, foi realizado em parceria com o Centro LatinoAmericano de Estudos de Violência e Saúde Jorge Careli e a Escola Nacional de Saúde Pública Sérgio Arouca, da Fundação Osvaldo Cruz (GOSCH, 2010).

Mesmo diante dessas iniciativas, a dificuldade de implementação da proposta da intersetorialidade tem sido um dos principais entraves para a concretização das ações e políticas de promoção da saúde. Para ilustrar tal afirmação, levantamse algumas áreas específicas dessas políticas e os desafios a elas atribuídos, mencionados em vários documentos, decretos e leis analisados. O objetivo de apresentar esses dados e abordá-los neste artigo é chamar a atenção sobre o tema e colocar em discussão a complexidade de tornar concretas práticas inter e intrassetoriais, especialmente as relacionadas À PNPS.

\section{A promoção da alimentação saudável}

A Política Nacional de Alimentação e Nutrição, junto com a PNPS, tem como um de seus objetivos o estímulo às práticas de alimentação saudável e a implementação de políticas públicas que garantam o acesso a uma alimentação de qualidade (BRASIL, s/d). Essa política propõe estratégias de estímulo à prática do aleitamento materno; de aumento do consumo de fruta e verduras; e de suplementação de nutrientes, além de apoiar a rotulagem nutricional nos alimentos processados e o 
monitoramento de agrotóxicos, através do Programa de Análise de Resíduos de Agrotóxicos da Agência Nacional de Vigilância Sanitária (BRASIL, 2008c).

Tais ações se articulam com outros setores e propõem parcerias diversas, entre as quais se destacam: a relação do Ministério da Saúde com o Ministério da Educação e com o Fundo Nacional de Desenvolvimento da Educação, para promover a alimentação saudável nas escolas; a parceria entre o MS e os Ministérios do Trabalho e Emprego, da Fazenda, da Previdência Social e de Desenvolvimento Social para estabelecer novos parâmetros para o Programa de Alimentação do Trabalhador (BRASIL, 2009a). Entretanto, existem aspectos que ainda precisam ser contemplados para atingir o complexo objetivo de promover uma alimentação saudável. Um deles diz respeito ao baixo envolvimento da temática com questôes de gênero e minorias, sendo essa instância parcialmente contemplada nas novas diretrizes da Política Nacional de Segurança Alimentar e do Programa de Alimentação Escolar, que se propõe a atender aos indígenas, quilombolas e assentados de forma diferenciada (BRASIL, 2010b; BRASIL, 2009b).

Outra dimensão remete à ausência de consenso para o que se considera uma alimentação saudável. Não se espera que este conceito seja unânime, considerando a dimensão cultural que circunda o ato de alimentar-se. Entretanto, é perceptível a existência de um conceito prevalente de alimentação saudável na sociedade brasileira, baseado em práticas restritivas e na visão energético-quantitativa da Nutrição moderna. Já o conceito contemporâneo de alimentação saudável assumido pela supramencionada Política Nacional de Segurança Alimentar e Nutricional inclui uma dimensão cultural e socioambiental e admite seu caráter polissêmico. Uma questão importante é pensar em como aproximá-los. Para o Conselho Nacional de Segurança Alimentar e Nutricional (CONSEA), a alimentação saudável e adequada é a realização de um direito humano básico, com a garantia ao acesso permanente e regular, de forma socialmente justa, a uma prática alimentar ajustada às necessidades biológicas e sociais dos indivíduos, de acordo com o ciclo de vida e as necessidades alimentares especiais, pautada no referencial tradicional local (BRASIL, 2010b). Ressalta-se que o termo adequada abrange os aspectos do desenvolvimento social e econômico baseado em um modelo de produção de alimentos que expresse a soberania alimentar e que, ao mesmo tempo, estimule a revalorização de métodos tradicionais de manejo e 
gestão ambiental, baseados nos conhecimentos acumulados de populações locais em sua íntima convivência com o meio natural e a otimização dos recursos disponíveis nos distintos lugares para atender a necessidade de reprodução biológica e social dos seres humanos (BRASIL, 2010b).

Assumir esse amplo conceito de alimentação saudável, ainda não incorporado por todas as políticas públicas, nem pela maioria das graduações em Nutrição, nos coloca diante de grandes desafios. Um deles é apoiar ou estreitar relaçôes com um sistema produtivo sustentável. Ou seja, as Políticas de Promoção de Saúde devem buscar estabelecer relações com as políticas de desenvolvimento rural, de agricultura familiar e de meio ambiente e encarar as ambiguidades existentes entre as diretrizes dessas áreas. Entre elas, destacam-se os subsídios do insustentável sistema moderno de agropecuária e do agronegócio de exportação, que coexistem com as tímidas políticas de suporte à agricultura familiar, à agroecologia e à preservação do meio ambiente.

Os principais programas que compõem a Política Nacional de Segurança Alimentar e Nutricional e garantem seu perfil intersetorial são: o Programa de Aquisição de Alimentos (PAA) e todas as iniciativas de fortalecimento da Agricultura Familiar; o Programa Nacional de Alimentação Escolar (PNAE) e o Programa Cisternas (BRASIL, 2010b).

O PAA incentiva a produção de alimentos pela agricultura familiar, permitindo a compra, a formação de estoques e a distribuição de alimentos para pessoas em situação de insegurança alimentar. Entre os objetivos do PNAE, ressaltam-se: a formação de hábitos alimentares saudáveis, a dinamização da economia local e o respeito aos hábitos regionais e vocação agrícola da região, revelando preocupações ambientais, através do incentivo à agroecologia, e sociais, pelo estímulo à aquisição de produtos da agricultura familiar (BRASIL, 2009b). O Programa Cisternas, do Ministério do Desenvolvimento Social e Combate à Fome, é reconhecido como uma política pública de democratização e acesso à água para a população de baixa renda, objetivando o desenvolvimento sustentável da região do semiárido brasileiro.

Para que tais políticas sejam coerentemente implementadas, é importante direcionar o olhar para além da problemática do desequilíbrio quantitativo da dieta e se debruçar sobre as temáticas da qualidade do alimento, do desenvolvimento rural sustentável, do sistema produtivo dominante e suas repercussōes socioambientais, bem como para as condições de saúde e qualidade de vida dos 
agricultores e consumidores. Outro desafio intersetorial da área de alimentação é a complexa questão do controle da propaganda de alimentos, uma vez que os direitos do cidadão à informação e à saúde não podem ser subjugados por questôes de estímulo ao consumo atendendo a valores capitalistas (MARINS et al., 2008).

Desde 2001, a rotulagem nutricional é uma obrigação nos alimentos processados no país. A resolução da ANVISA, de 2010, determina que fabricantes indiquem em embalagens e comerciais as quantidades utilizadas de açúcar, de gordura saturada, de gordura trans, de sódio e de bebidas, para que se possa verificar seu teor nutricional (BRASIL, 2010d) Essas ações ainda demandam aperfeiçoamento e novas políticas que protejam principalmente as crianças, com um esquema de controle intersetorial da propaganda por parte dos órgãos competentes, de associaçôes de consumidores e da sociedade como um todo.

\section{Atividade física}

As ações que envolvem práticas corporais e atividade física são as de maior destaque na PNPS. Dentro do enfoque de promoção de estilos de vida saudáveis, o Programa de Estímulo e Promoção da Atividade Física aproximou o MS dos Ministérios das Cidades, do Esporte, da Educação e da Cultura, e envolveu diferentes universidades e estados na Rede Nacional de Promoção da Saúde em vários municípios, na manutenção dos projetos financiados (BRASIL, 2009a).

Em 2009, foi lançado o Plano Nacional de Atividade Física, elaborado em conjunto com o Ministério do Esporte, com o objetivo de ampliar de 450 para mil o número de municípios que fazem parte da Rede Nacional de Práticas Corporais. Esses municípios terão acesso a projetos de incentivo ao lazer e atividades esportivas, como a construção de ciclovias e reforma de espaços públicos para a construção de locais para atividade física, denominados Academia das Cidades. E, com a liderança do Ministério da Saúde, uma rede de mais 500 secretarias de Saúde municipais e estaduais foi financiada em 2010 para o desenvolvimento de programas de promoção da atividade física (PRATT et al., 2010).

A implementação do projeto GUIA (Guide for Useful Interventions for Activity in Brazil and Latin America) no Brasil, apoiada pelo Centro Colaborativo de Atividade Física e Saúde do Centro de Controle e Prevenção de Doenças e da Organização Mundial da Saúde (OMS), tem o objetivo de produzir evidências sobre a efetividade de programas de atividade física realizados no país. O 
1342 projeto foi iniciado com a supracitada rede de financiamento do MS para apoio a projetos locais (PRATT et al., 2010).

Os dados acima, da avaliação interna da PNPS realizada pela Secretaria de Vigilância à Saúde do Ministério da Saúde (SVS/MS), demonstraram que apesar dos avanços, ainda existe uma mínima participação das demais Secretarias do Ministério da Saúde nos programas de atividade física, alimentação e promoção da paz e não-violência, desenvolvidos pela Rede Nacional de Promoção da Saúde. Este problema de integração intrassetorial foi detectado em alguns casos, por exemplo, pela participação pontual de outros setores do ministério e dos parceiros externos nas comemoraçōes do Dia Mundial de Atividade Física, que faz parte do Plano Nacional de Atividade Física. A mesma avaliação demonstrou, ainda, que apesar das campanhas para promoção da atividade física, estas têm ocorrido sob uma pequena difusão interna. Além disso, tem-se dado pouca ênfase ao fomento da autonomia do sujeito aos programas realizados, e poucas oportunidades à participação ativa dos usuários nas instâncias de decisão sobre a promoção da atividade física são oferecidas. A avaliação destaca, ainda, que a pouca ênfase nas práticas de participação social estende-se a todas as instâncias de atividades de promoção da saúde realizadas (BRASIL, 2010e).

\section{O controle do tabagismo na PNPS}

Desde 1989, o Instituto Nacional de Câncer, órgão auxiliar do Ministério da Saúde, articula a gestão e a governança do Programa Nacional de Controle do Tabagismo no Brasil, que tem como objetivo geral reduzir a prevalência de fumantes e a consequente morbi-mortalidade relacionada ao consumo de derivados do tabaco. As estratégias essenciais para o alcance desses resultados têm sido o fomento da rede de parcerias junto às secretarias estaduais e municipais de Saúde, outros setores do MS e do governo, assim como ONGs (BRASIL, 2003).

Apesar dos desafios de articular os vários segmentos e setores, as ações do Programa Nacional de Controle de Tabagismo estão entre as mais eficientes do Ministério da Saúde, uma vez que a política mescla ações educativas individuais voltadas para o uso do tabaco com açôes coletivas inter e intrassetoriais, como: o controle da mídia e da propaganda e o banimento de propagandas e atividades de promoção de produtos de tabaco, tanto diretas como indiretas; a inclusão de advertências sobre os malefícios do tabaco nas embalagens; impedimento de 
produção, importação e comercialização de alimentos sob a forma de derivados

do tabaco; proibição do uso de descritores nas embalagens e propagandas (como baixo teor, suave ou light); e as recentes leis antifumo em diferentes locais, normatizadas em diversos estados brasileiros.

A ação política ainda inclui intervenções estruturais como a elevação das alíquotas e impostos sobre cigarros importados ou nacionais, em 2009, e a articulação nacional junto à convenção-quadro sobre controle do uso de tabaco, da qual o Brasil foi signatário, em 2005 (BRASIL, 2003). A partir dessa articulação, foi criada a Comissão Nacional para Implementação da ConvençãoQuadro para Controle do Tabaco (CONICQ), formada por representantes de 16 ministérios e presidida pelo MS.

Entretanto, no seu esforço de avaliação das ações da PNPS, a equipe da SVS do Ministério da Saúde verificou também que tem havido pouca interação entre as atividades da CONICQ e as ações desenvolvidas pela Secretaria de Vigilância da Saúde, sob o controle do Conselho Gestor da PNPS, bem como a fraca relação com ONGs que já atuavam na defesa de ações relacionadas ao controle do tabaco. Também não existem estratégias previstas nessa política para reduzir danos do tabagismo sobre indivíduos já dependentes da nicotina, ações estas mais relacionadas com a Atenção Básica, cuja gestão é feita pela Secretaria de Atenção Básica do Ministério da Saúde e não pela Secretaria da Vigilância à Saúde. Esse contexto, identificado pela avaliação da SVS/MS, ilustra as lacunas existentes nas ações intrassetoriais dentro do Ministério da Saúde (BRASIL, 2010e).

Considerando que o preço do cigarro brasileiro ainda é um dos mais baratos do mundo, outro desafio para o programa, mencionado por Cavalcanti (2005), é dificultar o acesso ao cigarro para toda a população, reduzindo especialmente o acesso dos jovens aos produtos de tabaco. Isso depende de regulação das estratégias de venda, da política de preços dos produtos de tabaco e do controle do mercado ilegal de tabaco (que responde por cerca de $40 \%$ do consumo nacional e insere no mercado brasileiro produtos ainda mais baratos que os legais). A mesma autora ainda destaca a influência de grandes transacionais de tabaco que dominam o mercado nacional e mantêm contínuas estratégias de contraposição às ações de controle do tabagismo do Ministério da Saúde.

Muitos aspectos dessa trajetória de controle do tabagismo podem ser úteis para se pensar em programas de controle do consumo de alimentos prejudiciais à 
saúde e de álcool e drogas, sem que se ignore a pertinência da crítica às estratégias de culpabilização das próprias vítimas, utilizadas nessas ações main stream da PNPS (que também inclui a promoção da atividade física).

\section{A prevenção de violências nas políticas de promoção da saúde}

É perceptível o aumento de informações na mídia quanto aos riscos e danos envolvidos na associação entre o uso de álcool e outras drogas e o aumento da violência no trânsito. Entretanto, do mesmo modo que no caso do tabaco, as ações que envolvem a prevenção de acidentes de trânsito precisam de continuidade e/ou implementação, como é o caso das diretrizes do Código de Trânsito, instituído em 1997, do Comitê Nacional de Mobilização para a Saúde, Segurança e Paz no Trânsito, consolidado em 2007, e da Lei no 11.705 (Lei Seca), de 2008, que baixou os níveis de alcoolemia permitidos e a venda de bebidas alcoólicas em rodovias federais (BRASIL, 2010c). A pressão da área da saúde e dos usuários deve ser para se mantenha o controle do trânsito por meio de seus órgãos competentes, bem como o uso do bafômetro de forma regular e sistematizada em todo o país, o que não vem ocorrendo. Além disso, é preciso superar um complicador jurídico que envolve essa lei, que é a não-obrigatoriedade dos testes de dosagem alcoólica, sob o argumento de evitar a autoincriminação. Com isso, a definição de muitos crimes de trânsito não avança, gerando mais impunidade nas ações que envolvem acidentes e alcoolismo.

A articulação inicial do MS com outros ministérios (como o da Justiça e o das Cidades) para o monitoramento da Lei no 11.705 e o Projeto de Redução da Morbimortalidade junto aos Ministérios da Educação e do Meio Ambiente e as Secretarias Especiais de Direitos Humanos e da Juventude, além do apoio de ONGs, do setor privado, de instituições de ensino e pesquisa, de entidades científicas, de prefeituras e da sociedade civil organizada, mostraram resultados positivos. Ressaltam-se a redução de $23 \%$ nas internações por acidentes de trânsito, comparando-se o primeiro com o segundo semestre de 2008, e a diminuição de $22,5 \%$ na taxa de mortalidade nos óbitos por acidentes de trânsito entre 2007 e 2008 (BRASIL, 2009a). Destacam-se também a articulação e a parceria com a Escola Nacional de Saúde Pública e a Fundação Osvaldo Cruz, que têm como uma de suas atribuições avaliar as ações desenvolvidas por esse projeto.

Em paralelo a essas ações, o governo brasileiro lançou, em junho de 2010, 
o Projeto Vida no Trânsito, realizado em cinco capitais brasileiras - Teresina,

Palmas, Campo Grande, Belo Horizonte e Curitiba - e terá duas etapas. A primeira começou em 2010, estendendo-se até 2012. Até lá, as cidades selecionadas devem desenvolver experiências bem-sucedidas na prevenção de lesões e mortes provocadas pelo trânsito que possam ser reproduzidas por outras cidades brasileiras. A segunda etapa será realizada entre 2013 e 2015. Para a atuação das cidades, foram eleitos dois fatores de risco prioritários que devem nortear as medidas de prevenção: associação entre direção e bebida alcoólica e o excesso de velocidade. Os municípios poderão agregar outros fatores de risco, de acordo com a realidade local (BRASIL, 2010c).

O Projeto Vida no Trânsito teve origem com a escolha do Brasil para integrar uma ação global chamada Road Safety in 10 Countries. Além do Brasil, as diversas entidades coordenadoras selecionaram outros nove países para desenvolverem projetos de segurança no trânsito em função da sua alta taxa de mortalidade vinculada a acidentes nas estradas: Rússia, Turquia, China, Egito, Índia, Camboja, Quênia, México e Vietnã (BRASIL, 2010c).

O grupo que discutiu e elaborou o Projeto Vida no Trânsito é formado por representantes da Presidência da República - Casa Civil, Secretaria Nacional de Políticas sobre Drogas (Senad), do Gabinete de Segurança Institucional da Presidência da República, e Secretaria Especial de Direitos Humanos (SEDH), da Presidência da República; Ministérios da Saúde, Justiça/Polícia Rodoviária Federal (DPRF), Transportes, Cidades/Departamento Nacional de Trânsito e Secretaria Nacional de Mobilidade Urbana e Transporte -, bem como os Conselhos Nacionais de Secretários Estaduais de Saúde e Municipais de Saúde. Também integram o grupo representantes da OMS, da OPAS, da Bloomberg Philanthopies, da Universidade John Hopkins (JUH) e da Global Road Safety Partnership. Além desse projeto, o grupo interministerial brasileiro também está discutindo a proposta do país para o Plano de Ação de Redução de Lesões e Mortes no Trânsito, Segurança Viária e Cultura de Paz no Trânsito - Década 2011/2020, recomendada pela Organização das Nações Unidas (ONU) e OMS (BRASIL, 2010c).

Mesmo diante de resultados positivos, ainda se percebe a fragilidade da integração das ações entre os órgãos relacionados com a temática, devido às disputas políticas e partidárias, à cultura institucional, à burocracia e, entre outras 
razões, à descontinuidade nas ações e encontros entre o Ministério da Saúde, a Secretaria de Vigilância à Saúde, a Secretaria de Atenção Básica, o Ministério das Cidades e o Departamento Nacional de Trânsito (Denatran) (BRASIL, 2010c).

Destaca-se a implantação de espaços que têm estimulado a discussão também da violência doméstica e sexual; a violência de gênero, raça e cor; a violência no ambiente de trabalho e ensino, a tortura, o tráfico de pessoas, os homicídios, suicídios, entre outras. Um dos grandes problemas na área é que tem ocorrido pouca articulação da sociedade civil, uma das principais fontes de informação para o conhecimento de violências camufladas. Pensando nisso, foram criadas exitosas políticas, como a Estratégia Saúde da Família e o Programa de Agentes Comunitários e Saúde, que têm inserção na comunidade; e os Planos Nacionais de Enfrentamento de Violências - Violência Sexual Infanto-Juvenil; Violência Sexual e/ou Doméstica contra Mulheres; Violência contra Idosos e contra o Tráfico de Pessoas (BRASIL, 2008b).

O Ministério da Saúde, através da Secretaria de Vigilância à Saúde, implantou, em 2006, o Sistema de Vigilância de Violências e Acidentes (VIVA), com a finalidade de viabilizar a obtenção de dados através de fichas de notificação e instrumentos de entrada de dados e divulgação de informações sobre violências e acidentes, o que possibilitará conhecer a magnitude desses graves problemas de Saúde Coletiva. O projeto foi estruturado em dois componentes: vigilância contínua de violência doméstica, sexual, e/ou outras violências interpessoais e autoprovocadas; e vigilância sentinela de violências e acidentes em emergências hospitalares (BRASIL, 2006b). Desde 2006, foram realizados cursos para implantação desse sistema em hospitais e unidades básicas de saúde públicos, de forma a instruir os profissionais sobre o correto preenchimento desses dados que permitem aos gestores identificarem os principais tipos de violência, onde elas ocorrem, os horários de maior frequência e o perfil do possível autor da agressão, entre outras informaçóes, dando subsídios para o planejamento de ações de prevenção e de intervenção.

Em função de tal projeto, fortaleceram-se ações da Rede Nacional de Prevenção de Violências, Promoção da Saúde e Cultura de Paz e da Rede Nacional de Atenção Integral às Mulheres, Adolescentes e Crianças em situação de violência doméstica e sexual. Articulações intersetoriais diversas vêm-se efetivando, principalmente com as Secretarias Especiais de Políticas para Mulheres, com as Políticas de 
Promoção da Igualdade Racial e de Direitos Humanos da Presidência da

República e com os Ministérios da Justiça do Desenvolvimento Social e Combate à Fome, além dos Conselhos de Direitos da Criança e do Adolescente, de Escolas e outras instituiçôes educativas e dos Centros de Referência Especializados de Assistência Social (BRASIL, 2008b).

Uma das grandes dificuldades nessa área é o ainda incipiente envolvimento das instituições acadêmicas com órgãos competentes estaduais e municipais, enfim, a falta de integração intersetorial que dificulta o monitoramento das ocorrências e o distanciamento do setor não governamental no processo de implementação de um movimento social mais presente, bem como de políticas públicas de enfrentamento das violências. De qualquer forma, a temática vem ganhando destaque na Saúde Coletiva, com publicações especializadas como o número temático da Revista Ciência \& Saúde Coletiva, de 2009, que apresenta uma série de estudos sobre o impacto da violência na saúde (MORAES NETO et al., 2009).

\section{O desenvolvimento sustentável nas políticas de promoção da saúde}

O fomento ao desenvolvimento sustentável aparece na matriz de avaliação da PNPS pelos técnicos da SVS/MS com dados que permitem classificar esta área de atividade como um dos grandes desafios das políticas de promoção da saúde (BRASIL, 2010e). O próprio conceito de sustentabilidade assumido pelo Relatório Brundtland (1991) já pressupõe ações intersetoriais, uma vez que inclui uma perspectiva de desenvolvimento que supera a visão desenvolvimentista moderna e acolhe os âmbitos social, ambiental, cultural e econômico. Existem atualmente algumas propostas da PNPS voltadas ao desenvolvimento rural sustentável, entre as quais se destaca o programa, ainda não implementado, Territórios da Cidadania, que objetiva principalmente minimizar a pobreza rural por meio da geração de trabalho e renda para populações de agricultores, quilombolas e indígenas (BRASIL, 2009a).

Outra iniciativa que deveria ir ao encontro das necessidades das populações rurais é a Política Nacional de Saúde Integral das Populações do Campo e das Florestas, construída com a participação de representantes de movimentos sociais, sob a coordenação da Secretaria de Gestão Estratégica e Participativa do MS. Seu principal objetivo é garantir o acesso à saúde às populações desse território, promovendo a qualidade de vida e respeitando as especificidades 
1348 do mesmo. A política foi aprovada por unanimidade no Conselho Nacional de Saúde, mas ainda não foi pactuada na Comissão Intergestores Tripartite (CIT), que reúne representantes de gestores do SUS das três esferas de governo. Pretende-se que o documento, ao ser levado para a CIT pela terceira vez, (o que mostra a baixa prioridade do tema da saúde rural), consiga obter sua pactuação (RODRIGUES, 2010).

Os já mencionados Programa de Alimentação Escolar e a Política Nacional de Segurança Alimentar e Nutricional, bem como as Políticas de Programas de Apoio à Agricultura Familiar e a recém-instituída Política Nacional de Agroecologia e Agricultura Orgânica são iniciativas que se voltam ao desenvolvimento rural sustentável através do incentivo à produção orgânica, a concessão de crédito, seguro, assistência técnica e pesquisa, para ampliar a produção de base agroecológica no Brasil, centralizando as necessidades do agricultor familiar.

Para fortalecer o desenvolvimento rural sustentável e a área de saúde rural, julga-se necessário estreitar relações entre as Secretarias de Gestão Estratégica e Participativa e de Vigilância à Saúde do MS com as comunidades locais. Considerando a atividade agrária como central nesse meio e também as repercussões socioambientais do sistema agroalimentar e dos agrotóxicos e outros contaminantes da agricultura convencional sobre a saúde humana, é preciso haver um diálogo mais efetivo do MS com ministérios e entidades do Meio Ambiente, da Agricultura e o do Desenvolvimento Agrário, o que não tem acontecido.

Azevedo e Pelicioni (2012) enfatizam, em estudo, a falta de diálogo entre especialistas das áreas de agroecologia e de promoção da saúde. Para as autoras, essas duas áreas são contributivas e complementares e sua aproximação pode vir a enriquecer a discussão da saúde rural e a concepção das políticas públicas que se debrucem sobre a temática, estimulando intervenções e práticas intersetoriais.

Um instrumento que pode embasar futuras políticas interventivas é o Mapa de Conflitos, ${ }^{1}$ envolvendo injustiça ambiental e saúde no Brasil, construído em parceria com a Fundação Osvaldo Cruz e a ONG Fase, apoiado pelo Departamento de Saúde Ambiental e Saúde do Trabalhador da Secretaria de Vigilância à Saúde do MS. O mapa produz informaçôes sobre populações e grupos atingidos em seus territórios por projetos e políticas, baseadas numa visão de desenvolvimento insustentável e prejudicial à saúde que influencia em seus modos de vida e sua segurança. 
A discussão sobre desenvolvimento sustentável é transversal em políticas que atendem às necessidades das minorias, como a Política Nacional de Atenção à Saúde dos Povos Indígenas, que reconhece as especificidades étnicas e culturais, o direito de inclusão nos processos decisórios e os direitos territoriais dos povos indígenas, aspectos decisivos para fomentar a sustentabilidade.

A abordagem do desenvolvimento sustentável no meio urbano aparece em intervenções municipais, como o Programa Saúde na Escola e a Agenda Cidades Saudáveis (BRASIL, 2009a).

O Programa Saúde na Escola é resultado de uma ação interministerial entre os Ministérios da Saúde e da Educação, em parceria com a Organização das Nações Unidas para a Educação, a Ciência e a Cultura, o Fundo das Nações Unidas para Crianças e o Fundo das Nações Unidas para Atividades Populacionais (BRASIL, 2009a).

A iniciativa Cidades Saudáveis identifica aspectos determinantes do processo saúde-doença, especificamente nas regiōes urbanas e periurbanas. Destaca-se a necessidade de criar uma proposta interministerial para seu fomento, bem como estimular a participação social das comunidades e de seus representantes. Várias tentativas têm sido feitas pelos profissionais e professores da área de Promoção da Saúde, mas até agora nada de concreto ocorreu para fortalecer esta atividade da PNPS.

Permanece o desafio intersetorial da promoção do desenvolvimento sustentável, que além de não ter sido ainda apoiado por ações concretas da SVS do Conselho Gestor da Política Nacional de Promoção da Saúde, revela também a dificuldade de integração existente nas atividades realizadas dentro do próprio Ministério da Saúde, uma desconexão reincidente em outras ações supramencionadas.

\section{Considerações finais}

Os setores da educação e da ação social parecem ser os parceiros mais comuns nas ações intersetoriais das Políticas Públicas de Promoção da Saúde, apesar da evidente centralização no setor saúde (MENDES, 2000). Essas parcerias devem proliferar, uma vez que se evidenciam cada vez mais ações e diretrizes intersetoriais em diferentes políticas públicas. A perspectiva de atuações inter e intrassetoriais no campo das políticas de saúde tende a se expandir, uma vez que não é mais possível retroceder na discussão que envolve a ampla causalidade 
do processo saúde-doença. A partir de uma abordagem intersetorial que vise à melhoria das condições de vida, a saúde se torna um objetivo a ser alcançado por todas as políticas públicas que têm como diretriz a promoção da qualidade de vida das populaçôes, ampliando o entendimento do termo saúde. Diante disso, a seguir são resumidos alguns problemas e soluções mais evidentes relacionados às políticas e açõos de promoção da saúde e prática da intersetorialidade.

Ressalta-se a falta de reconhecimento de alguns dos temas como problemas inerentes à Saúde Coletiva, como é o caso das violências, bem como despreparo técnico-político de gestores e profissionais da saúde no desenvolvimento de ações intersetoriais de prevenção e promoção e as dificuldades burocráticas e ausência de financiamento de ações intersetoriais para concretizá-las.

Moyses et al. (2004, p. 631) sinalizam outra dificuldade na gestão da saúde pela via da intersetorialidade, que se relaciona:

[...] ao rompimento de relações tradicionais de trabalho, em que o segmento que detém o poder acaba prevalecendo nos processos de decisão, aliada à dificuldade de profissionais de saúde em olhar para além do objeto específico de sua atuação, muitas vezes em situações contaminadas pelo corporativismo profissional, caracterizam aspectos da cultura institucional geral do setor público. Além disso, as rubricas dos orçamentos públicos são predominantemente setorizadas, o que reforça a dificuldade de compartilhamento de poder entre os atores envolvidos e dificulta a agilização e resolutividade das ações.

Essa problemática tende a diminuir à medida que as instituições de ensino incorporem a interdisciplinaridade como diretriz dos cursos de graduação da área da saúde. Tal perspectiva é mais explorada no âmbito das pós-graduações em saúde e de instituições de pesquisa e extensão. Apesar de já ter iniciado o processo de capacitação de gestores em promoção da saúde, muitos dos docentes da área da saúde e dos profissionais atuantes no SUS e na Saúde Pública/Coletiva ainda não tiveram a oportunidade de reciclar conhecimentos e ampliar suas visões de saúde, problematizando o conceito de interdisciplinaridade que fomenta práticas inter e intrassetoriais. Em muitas instâncias, persiste o enfoque preventivista e a visão biomédica que embasam ações setoriais.

No nível das graduações, existe ainda a problemática da pressão de enquadrar os cursos das áreas da saúde em critérios que priorizam equipes com formações disciplinares. Muitos dos concursos indeferem profissionais com titulaçōes em áreas de pós-graduação consideradas "não-afins", o que acaba resultando em cursos sem visão interdisciplinar e prática intersetorial. Volta-se à questão 
acima, ou seja, a dificuldade de encontrar profissionais e docentes com visão

interdisciplinar é uma decorrência dos currículos dos cursos de graduação que ainda formam profissionais desmotivados e desqualificados para encarar os desafios que a intersetorialidade impõe. Essa dimensão chama atenção para a necessidade de criar uma diretriz específica na PNPS que apoie processos continuados de formação de recursos humanos e reestruturação de cursos de graduação da área da saúde, colocando-os em sintonia com os princípios da promoção da saúde, além de ampliar espaços de reflexão e diálogo em todas as instâncias de educação para implementar tais políticas. Destaca-se também a necessidade de ampliar os campos de ação do Conselho Gestor da PNPS, para que os seus integrantes revejam seu posicionamento no Ministério da Saúde, facilitando a integração interministérios.

Revendo as açôes propostas por essas políticas, percebe-se, com pouca ênfase, o estímulo à participação social, cujas práticas devem ser revistas. Os atores locais são uma dimensão intersetorial específica, desprendidos dos setores formais vinculados à promoção da saúde, mas que também podem ser considerados como legítimos agentes consultivos, planejadores e avaliadores das açôes das políticas de promoção da saúde. Para que essa inserção ocorra, a avaliação da comunidade e a análise do território são essenciais, já que a ação decorrente desse olhar tende a ser diferente daquela proposta pelo Ministério da Saúde. Uma sugestão é que técnicos do ministério ou de pontos focais de promoção da saúde do país apoiem a execução dos projetos que o ministério vem financiando, incentivando intervenções mais criativas e mobilizadoras de agentes e atores, ajustadas às realidades locais. Dessa forma, pode ser alcançada a diretriz da PNPS, que objetiva "fortalecer a participação social como fundamental na consecução de resultados de promoção da saúde, em especial a equidade e o empoderamento individual e comunitário" (BRASIL, 2006a).

Em suma, as políticas públicas de Promoção da Saúde, ao valorizarem a perspectiva territorial e as redes, potencializam os processos participativos e integrados, de estímulo à autonomia e ao controle social, estreitando vínculos para apoiar grupos no enfrentamento de situações diversas ainda não percebidas como necessidades.

A crítica à visão comportamental é pertinente, uma vez que a cultura normativa é ainda expressiva no setor da saúde, no qual as ações são 
1352 frequentemente reguladas por normas centralizadas, reforçando atitudes hegemônicas e autoritárias, de responsabilização dos indivíduos por sua maneira de viver. Sofisticam-se, cada vez mais, estratégias de culpabilização das próprias vítimas, a exemplo das campanhas de controle do tabagismo e de estímulo à alimentação saudável e aos exercícios físicos.

Por fim, todas essas propostas são insuficientes para implementar intervenções políticas de promoção da saúde, sem que haja um concomitante processo de ativação do sujeito nas ações intersetoriais. O sujeito social - gestor, técnico, profissional ou usuário - mobilizado para decisões intersetoriais de promoção da saúde, deve estar aberto à revisão de posturas hierárquicas e centralizadoras, relativizando os interesses pessoais e a suposta segurança institucional relacionada a alguns formatos de cargos públicos. Uma incorporação sadia do sujeito nos processos decisórios se traduz em reflexões críticas sobre as próprias práticas, em posturas solidárias, comprometidas e generosas que visem ao bem estar comum, além de disponibilidade para o diálogo e para a mudança. ${ }^{2}$

\section{Referências}

AZEVEDO, E.; PELICIONI, M.C.F. Agroecologia e promoção da saúde no Brasil. Rev Panam Salud Publica, v. 31, n. 4, p. 290-5, 2012.

BRASIL. Ministério da Saúde. Secretaria de Vigilância em Saúde Departamento de Análise de Situação de Saúde. Coordenação Geral de Doenças e Agravos Não Transmissíveis. Portaria no184 de 24 de Junho de 2010a. Disponível em: <http://portal.saude.gov.br/portal/ arquivos/pdf/portaria_184_2010_ms_svs_cgdant.pdf> Acesso em: 16 dez 2012.

BRASIL. Decreto no 7.272, de 25 de Agosto de 2010. Regulamenta a Lei no 11.346, que cria o Sistema Nacional de Segurança Alimentar e Nutricional. Diário Oficial [da] Uniāo, 26 ago 2010b. Disponível em: <http://www.planalto.gov.br/ccivil_03/_ato2007-2010/2010/ decreto/d7272.htm> Acesso em: $12 \mathrm{dez} 2012$.

BRASIL. Ministério da Saúde. Secretaria de Vigilância em Saúde. SVS em Rede. Brasil integra projeto para reduzir lesóes e mortes no trânsito. 2010c. Disponível em: <http://189.28.128.179:8080/svs_informa/edicao-72-abril-de-2010/brasil-integra-projetopara-reduzir-lesoes-e-mortes-no-transito> Acesso em: 3 abr. 2011.

BRASIL. Resolução Anvisa no 24, de 15 de Junho de 2010. Dispõe sobre critérios para a divulgação de produtos alimentícios. Diário Oficial [da] Uniāo, 29 jun 2010d. Disponível em: <http://www.vigilanciasanitaria.sc.gov.br/index.php?option=com_docman \&task=doc_ download\&gid=704> Acesso em: $16 \mathrm{dez} 2012$. 
BRASIL Ministério da Saúde. Secretaria de Vigilância a Saúde. Planilhas de matriciamento

dos avanços e desafios das prioridades da PNPS: ações propostas e realizadas durante 20062009. Brasília, 2010e[mimeo].

BRASIL. Ministério da Saúde. Promoção da Saúde V. Brasília: OPAS, 2009a (Painel de Indicadores do SUS n. 6).

BRASIL. Lei n ${ }^{\circ} 11.947$, de 16 de Junho de 2009. Dispõe sobre o atendimento da alimentação escolar e do Programa Dinheiro Direto na Escola aos alunos da educação básica. Diário Oficial [da] União, 17 jun 2009b. Disponível em: <http:/www.planalto.gov.br/ccivil_03/_ ato2007-2010/2009/lei/111947.htm> Acesso em: 16 dez. 2012.

BRASIL. Ministério da Saúde. Secretaria de Vigilância em Saúde. Portaria no 68 de 24 de junho de 2008. Constitui o Comitê Gestor da Política Nacional de Promoção da Saúde. Disponível em: <http://bvsms.saude.gov.br/bvs/saudelegis/svs/2008/ prt0068_24_06_2008.html> Acesso em: 16 dez. 2012.

BRASIL. Ministério da Saúde. Prevenção de Violências e Cultura da Paz III. Brasília: OPAS, 2008b (Painel de Indicadores do SUS n. 5).

BRASIL. Agência Nacional de Vigilância Sanitária. Relatório Anual do Programa Nacional de Análise de Resíduos de Agrotóxicos em Alimento. Brasília: Ministério da Saúde. 2008c. Disponível em: <http://www.anvisa.gov.br/toxicologia/residuos/resultados_PARA_2008. pdf> Acesso em: 5 ago. 2009.

BRASIL. Ministério da Saúde. Política Nacional de Promoção da Saúde. Brasília: Ministério da Saúde. 2006a. Disponível em: <http://bvsms.saude.gov.br/bvs/publicacoes/politica_ nacional_promocao_saude_3ed.pdf> Acesso em: 6 dez. 2010.

BRASIL. Ministério da Saúde. Portal da Saúde. Sistema de Vigilância de Violências e Acidentes (VIVA). 2006b. Disponível em: <http://portal.saude.gov.br/portal/saude/profissional/ visualizar_texto.cfm?idtxt=32127\#processo $>$ Acesso em: 19 dez. 2010.

BRASIL. Ministério da Saúde. Instituto Nacional do Câncer. Programa Nacional de Controle do Tabagismo e Outros Fatores de Risco de Câncer. 2003. Disponível em: <http://www1. inca.gov.br/tabagismo/frameset.asp?item =programa\&link=programa_de_tabagismo.pdf $>$ Acesso em: 16 dez.2012.

BRASIL. Ministério da Saúde. Política Nacional de Alimentação e Nutrição. Brasília: Ministério da Saúde, s/d. Disponível em: <http://www.brasilsus.com.br/legislacoes/ svs/104499-184.html> Acesso em: 8 fev. 2011.

BUSS, P.M. Promoção da saúde e qualidade de vida. Rev C S Col. Rio de Janeiro, v.5, n.1, p. $163-178,2000$.

CAMPOS, G.V.; BARROS, R.B.; CASTRO, A.D. Avaliação de política nacional de promoção da saúde. Rev C S Col. Rio de Janeiro, v. 9, n. 3, p. 745-749, 2004. 
CAVALCANTI, T.M. O controle do tabagismo no Brasil: avanços e desafios. Rev. Psiq. Clin. v.32, n. 5, p. 283-300, 2005.

DELEUZE, G.; GUATTARI. F. Mil platôs: capitalismo e esquizofrenia. São Paulo: Editora 34, 1995.

FEUERWERKER, L.M.; COSTA, H. Intersetorialidade na rede Unida. Saúde em Debate. Rio de Janeiro, v.22, p. 25-35, 2000.

GOSCH, C.S. Política Nacional de Promoção da Saúde: a construção da Rede Nacional de Promoção da Saúde, 2010. In: FÓRUM BRASILEIRO DE PROMOÇÃO DA SAÚDE DA ASSOCIAÇÃO BRASILEIRA DE PROMOÇÃO EM SAÚDE, 7. Disponível em: <http:// www.abps.org.br/publicacao.html> Acesso em: 8 dez. 2010.

INOJOSA, R.M. Intersetorialidade e configuração de um novo paradigma organizacional. Rev Adm. Pub. Rio de Janeiro, v.32, n.2, p. 35-48, 1998.

JUNQUEIRA, L.A.P. Descentralização e intersetorialidade: a construção de um modelo de gestão municipal. Rev Adm. Pub. Rio de Janeiro, v. 32, n. 2, p. 11-22, 1998.

MARINS, B.R.; ARAÚJO, I.S.A.; JACOB, S.C. A Propaganda de Alimentos: orientação ou apenas estímulo ao consumo? Rev C S Col. Rio de Janeiro, v. 16, n. 9, p. 3873-3882, set 2011.

MENDES, E.V. Uma agenda para a saúde. São Paulo: Hucitec, 1996.

MENDES, R.; AKERMAN, M. Intersetorialidade: reflexões e práticas. In: FERNANDES, J.C.A.; MENDES, R. (Org.). Promoção da saúde e gestão local. São Paulo: Aderaldo \& Rothschild, 2007. p. 85-109.

MENDES, R. Cidades saudáveis no Brasil e os processos participativos: os casos de Jundiaí e Maceió. 2000. 229p. Tese (Doutorado em Saúde Pública) - Faculdade de Saúde Pública, Universidade de São Paulo, São Paulo, 2000.

MORAES NETO, O.L.; MALTA, D.C.; SILVA, M.M.A. Promoção à saúde e vigilância de violências: efetividade e perspectivas. Ciênc. saúde coletiva. Rio de Janeiro, v. 14, n. 5, p. , 2009.

PELICIONI, M.C.F. Promoção da saúde e meio ambiente: uma trajetória técnico-política. In: PHILIPPI JR., A.; PELICIONI, M.C.F (Org.). Educação ambiental e sustentabilidade. São Paulo: Manole, 2005. p. 413-20.

PRATT, M. et al.Projeto GUIA: um modelo para compreender e promover a atividade física no Brasil e na América Latina. J Phys Activ Health, v.7, n.2. p. S131-S134, 2010.

RELATÓRIO BRUNDTLAND. Nosso Futuro Comum. Comissão Mundial sobre Meio Ambiente e Desenvolvimento. Rio de Janeiro: Fundação Getúlio Vargas, 1991.

RODRIGUES, T. EPSJV: debate modelos de desenvolvimento para as populações do campo. 2010. Disponível em <http://www.epsjv.fiocruz.br/index.php?Area=NoticiaIntern a\&Destaques $=0 \&$ Num $=129>$ Acesso em: 6 fev. 2011. 
VERDI, M.; CAPONI, S. Reflexões sobre a promoção da saúde numa perspectiva bioética.

Texto Contexto Enferm, Florianópolis, v.12, n.1, p. 82-88, 2005.

WESTPHAL, M.F. Promoção da saúde e prevenção de doenças. In: CAMPOS, G.W.S.; MINAYO, M.C.A.; AKERMAN, M. et al. (Org.). Tratado de Saúde Coletiva. Rio de Janeiro: Fiocruz, 2006. p. 635-667.

\section{Notas}

${ }^{1}$ Informação e mapa disponíveis em: http://www.conflitoambiental.icict.fiocruz.br/ Acesso em: 25 set. 2012.

${ }^{2}$ E. Azevedo concebeu o artigo e todas as autoras participaram da elaboração e da revisão do texto. 


\section{Intersectoral practices in public policies for health promotion}

This review examines some public policies established between 2006 and 2010 that dialogue with the guidelines of Health Promotion, in order to investigate how intersectorality permeates their actions. Intersectoriality is able to revitalize such policies, encouraging health promotion actions that address the complex determinants of the disease process. However, some problems showed up to meet this challenge. Noteworthy is the unpreparedness of political and technical managers and health professionals to take intersectoral actions and administrative matters that hinder the implementation of integrated actions. This unpreparedness leads, among other damages, to the lack of recognition of some themes of the policies as legitimate questions of public health. Moreover, many remain in the policy agendas, centralized decisions that prevent community participation and the emergence of problems adjusted to local realities, whose solutions require intersectoral and creative interventions. Thus, it becomes essential to foster an effective educational process to form interdisciplinary health professionals with intersectoral viewpoint in line with the guidelines of public policies to promote health. It is also important to highlight the territorial dimension and social networks, improving participatory processes that enhance the intersectoral perspective of these policies, as well as to stimulate the activation of the subject in decision making.

> Key words: intersectoral practices; health promotion; public policies. 